\title{
Inclusive Model Application Using Accessible Learning Objects to Support the Teaching of Mathematics
}

\author{
Andreza Bastos MOURÃO ${ }^{1,2}$, José Francisco de Magalhães NETTO ${ }^{1}$ \\ ${ }^{1}$ Federal University of Amazonas (UFAM) \\ ${ }^{2}$ State University of Amazonas (UEA) \\ Manaus, Amazonas, Brazil \\ e-mail:amourao@uea.edu.br,jnetto@icomp.ufam.edu.br
}

Received: November 2018

\begin{abstract}
This article presents an experience report regarding the application of an Inclusive Model of Development of Accessible Learning Objects, in the Mathematics discipline, to help 8th year Elementary School children, to perform calculations with natural numbers. The Learning Object was developed using Scratch and accessibility guidelines to include students with disabilities. The model evaluated the learning, teaching, usability, and accessibility of objects. The results demonstrate the efficiency, interaction and improvement in students' performance in Mathematics, through the use of objects in the teaching and learning process.
\end{abstract}

Keywords: accessible learning object, disabilities, learning, mathematics.

\section{Introduction}

The training of professionals in the area of Informatics in Education requires teaching based on theories and educational epistemologies, and in the key disciplines of the computing area. Allowing to acquire: competencies and skills in the performance of their professional activities.

Inclusive Models are actions that have been generating significant contributions in the educational scenario. International and national human rights agreements, covenants and legislation provide definitions that focus on equity, access, opportunity and rights (Forlin and Chambers, 2013). It is important to realize that all students can learn in different ways, the teachers need to identify the different learning styles and the way that students learn (Mourão and Netto, 2018a).

Based on the conceptions of the Brazil National Curricular Guidelines for Undergraduate Courses in Computer Science (Brazil, 2016), one of the objectives is develop 
into students their capacity to act as teachers, stimulating the investigative attitude with a critical and reflective view. In this way, the educators are motivated to apply the computation and its technologies in the processes of planning and management of teaching, contributing with the learning in schools and in organizations, getting experience during the supervised internship. According to Modeste (2016) the development and interaction of Mathematics and Informatics are from the didactic point of view very important for the students.

Mathematics is one of the areas in which children present a greater learning difficulty. According to Kuřina (2008), solving mathematical tasks and problems using mathematical tools and techniques is the foundation of good school Mathematics. The students must be able to solve problems because solving problems are important for the development of human competencies (Tambychik and Subahan, 2010). For authors, in real life, students need to solve problems because that is a basic way to survive in our daily life and Mathematics is seen as a language.

Promoting and investing in digital media for basic, fundamental and average education can help achieve educational goals. Freire (1996) points out that the didactic approach must take into account students' realities, encouraging them to appropriate knowledge and develop epistemological curiosity. Learning Object (LO) is one of the main research topics in the learning community in recent years, publications about LO and Accessible Learning Object (ALO) has been gaining repercussion (Borges et al., 2016) and (Mourão and Netto, 2016). Learning Objects fit into this scenario, corresponding to any digital resources that can be used to support teaching (Wiley, 2001).

This article aims to present an Experience Report regarding the application of the Inclusive Model proposed by (Mourão and Netto, 2016). The development and application of the object were accomplished by a finalist student of the University Degree in Computer Science during her period of Supervised Internship.

The Accessible Learning Object was applied in the Mathematics discipline to work with natural numbers, 40 students participated, of these one Students with Disabilities (SwD), between the age 12 and 14 years old, from the 8 th year of the afternoon period. We applied the objects in Elementary course and public school in the city of Manaus/ Amazonas in Brazil. Through the Inclusive Model, it was possible to collect data about students' motivation, experience, and learning. By means of the study, hoped to encourage initiatives for the insertion of Accessible Learning Objects in primary, elementary, secondary and higher education, in order to meet the recent demands of Students with Disabilities. However, the proposed methodology can be extended to other learning areas.

This article discusses in section 1 a brief background on Informatics in Education and Inclusive Model of ALO. The following sections present the proposed scientific methodology. Subsequently, we present some information about the production and practical experience, including illustrating them.

Further, section 5 presents the results obtained with of the ALO developed. Finally, the conclusions are presented. 


\section{Methodology}

The methodology used for the construction (Fig. 1), accomplished and application of the Accessible Learning Object was specified in three phases, as described below:

1. Planning: in this phase, the lesson plan was elaborated together with the Mathematics teacher. Where was defined and developed the following items: Pedagogical Approach, Lesson Plan, Schedule and Pedagogical Design.

2. Development: in this stage, the Accessible Learning Object was developed, based on the Model defined by (Mourão and Netto, 2016). Thus, was defined as a parameter the Accessibility Guidelines proposed by Macedo and Ulbricht (2012), and we used the Scratch tool for the construction of the Mathematics OAA. The Scratch tool is excellent for teaching Mathematics (Shimohara and Sobreira, 2015).

3. Student Performance Evaluation: this phase presents the performance results obtained by the students, based on the activities developed with the Learning Objects. In this sense, intended to help the teacher to obtain an assessment of student performance. For validation of ALO, was used the evaluation model proposed by (Mourão and Netto, 2018b). The model consists of a questionnaire and the evaluation of specialists to highlight the level of teaching and learning achieved by the students, as well the accessibility and usability items of ALO.

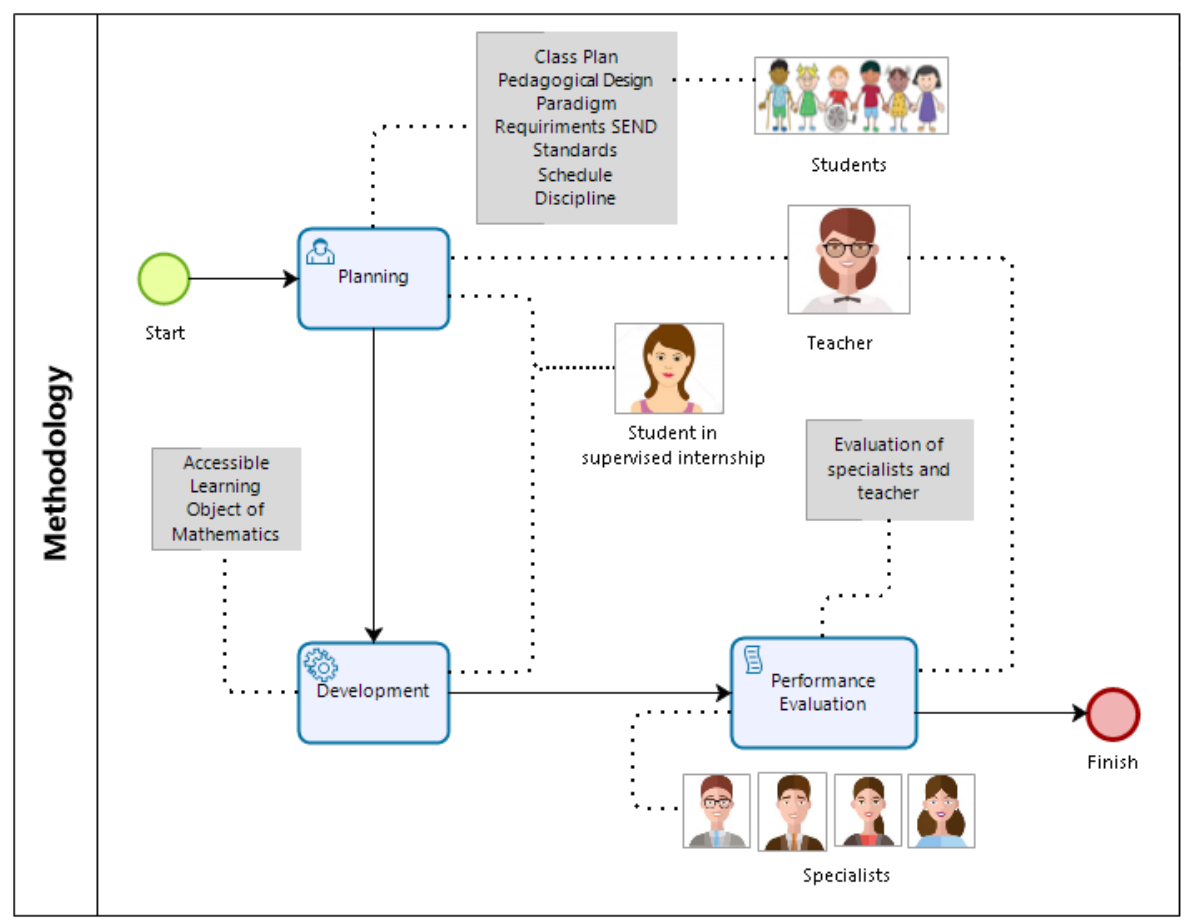

Fig. 1. Methodology for the ALO construction. 


\subsection{Methodology Application}

This section describes how the methodology was applied to get the expected results that can be visualized by means of the experience report shown in section 3 .

\subsubsection{Planning}

In this phase, the Accessible Learning Object developed followed the methodology that suggests four steps proposed by (Mourão and Netto, 2018b). Fig. 2 depicts the developed model to attend students with disabilities.

After that was started planning the learning object. In this sense, were defined: instructional unit, educational objectives, resources and media. However, for the design of the ALO was using the Storyboard technique and considering the guidelines defined by Macedo and Ulbricht (2012), which emphasizes that all content of an Accessible Learning Object must present at least: an equivalent media, in a different format or an alternative media; and an equivalent or alternative textual access media.

\subsubsection{Development}

Development phase consisted of the ALO implementation as described in the pedagogical approach analysis from (Mourão and Netto, 2018b), shown in Fig. 2.

The ALO was design and developed by the student of the course of degree in Computer in its period of supervised internship in parallel with the professor of the discipline of Mathematics, using the authoring software. The tool chosen was Scratch (Resnick, 2009), for meeting the objectives and requirements defined by the project and the familiarization of team members with their use. The Scratch Environment is a visual programming language that allows the creation of games, animations, and stories in a playful and interactive way.

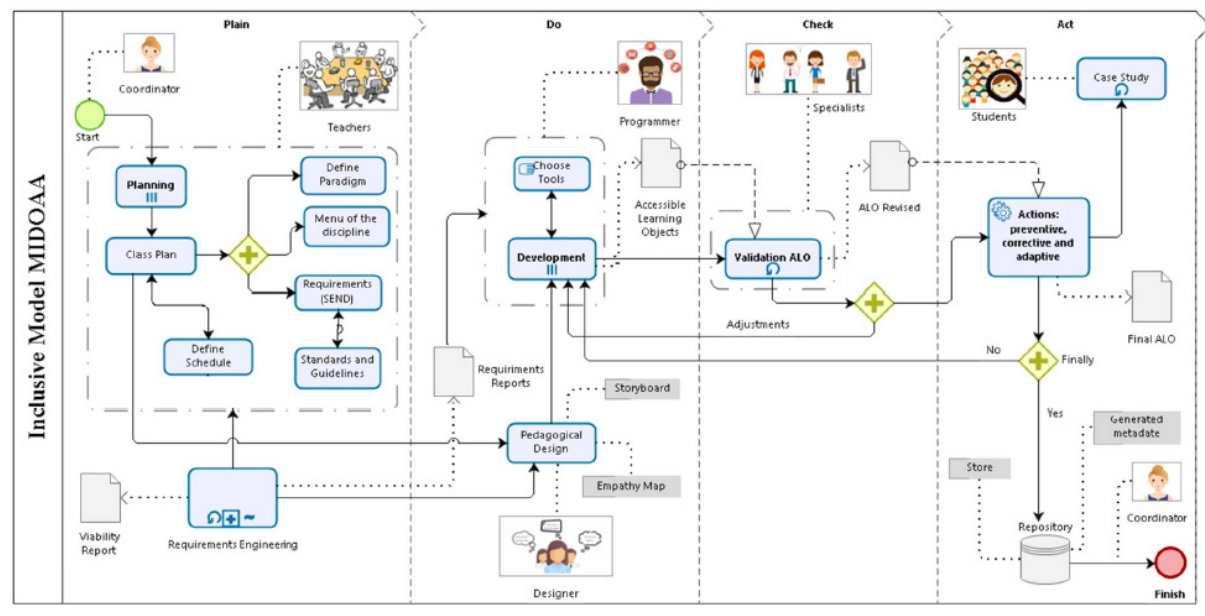

Fig. 2. Inclusive Model proposed by (Mourão and Netto, 2018b). 


\subsubsection{Student Performance Evaluation}

Performance Evaluation phase, the students were evaluated in relation to content, teaching and learning items, and finally, the objects were evaluated in relation to usability and accessibility items.

Student's performance and the evaluation of learning objects occurred in the last two weeks, as shown in Fig. 4. Specialists of areas of Pedagogy and Informatics in Education, participated in the application of the model. A questionnaire was applied to obtain significant quantitative data based on expert opinion as suggested by (Mourão and Netto, 2018b). The discipline's teacher applied a test with the students before and after the use of the ALO, with the objective to get an evaluation note and a concept about the use of this model in his classroom.

\section{Experience Report}

Based on the methodology in Section 2, Accessible Learning Object for the teaching of Mathematics (calculations with natural numbers) was planned and developed for to teach students of the 8 th grade, of the municipal school. The development of the ALO and the application of the Inclusive Model was the result of the experience acquired by one student in the supervised internship, matriculate in 7th (seventh semester), of Degree in Computing course, in the Advanced Topics discipline.

For Bianchi et al. (2005), the Supervised Internship is an experience, which the student demonstrates his creativity, independence, and character. The supervised internship is a necessary process for undergraduate courses. In this way, it enables the practice through the experience in the school environment, where students develop their professional skills and competencies based on theories and practices obtained in the classroom.

According to Nagyivá (2018), Mathematics and Informatics are extremely similar, considering their historical development. For the author, both are sciences focused on solving problems, especially considering the instruction of Mathematics and Informatics, respectively. Wolfram (2010) related in your paper, which Mathematics education, can be conducted through Informatics and Computers.

The student of the Degree in Computer Science developed her practice with the support of the Mathematics teacher and the teacher responsible for the Inclusive Model. Thus, the steps necessary to achieve the learning objectives specified with the selected class have been started. The process began during the teachers' planning period, where meetings were accomplished to define the methodology of teaching, content, and practice.

The instructional unit to be worked was defined by the teacher of the discipline, aiming to attend the first part of the program shown in Table 1.

In this way, the program was divided:

1. Preliminary notions,

2. Functions,

3. Limits Theory, 
Table 1

The Mathematics Discipline Program

\begin{tabular}{l}
\hline Program (defined by the School) \\
\hline 1. Mathematics \\
1.1 Numbers \\
1.2 Rules of Three Simple and Compound \\
1.3 Functions \\
1.4 Real Function Theory \\
1.5 Limits \\
\hline
\end{tabular}

4. Continuity and

5. Limitation of functions and derivatives.

Thus, the programmatic contents of preliminary notions were defined, as can be seen in Table 2.

At the same time, the pedagogical approach was defined, the conditions (physical, hardware and software) Computer laboratory provided by the school were analyzed and evaluated. The laboratory consisted of fifteen Computers, air conditioner, a multimedia projector, and a large meeting table. In this way, as the infrastructure met the needs of the project, it advanced to the next stage.

In the planning meetings, the scope of the lesson plan and learning objectives regarding the contents were defined as can be observed in Table 3.

Learning objects were developed considering the subject of natural numbers. The implementation of other objects, considering the other subjects would be developed if there were time and interest of the teacher of the discipline.

After preparation of the lesson plan, the student made the production of didactic material (Accessible Learning Objects), considering the students profile and the content. It is important to note that the classroom chosen for the development and application of the objects had a student with a hearing impairment.

Table 2

Lesson plan of classes (stretch) \#1- Preliminary Notions

Content (defined by the Professor)

1. Fundamentals

1.1 Natural, Integer, Rational, and Real Numbers

1.2 Potentiation

1.3 Radiation

1.4 Equations and Inequities

1.5 Resolution of Equations Systems

1.6 Rationale and Proportion

1.7 Three simple and compound rules 
Table 3

Sequence of the programmatic content - Preliminary Notions

\begin{tabular}{lll}
\hline $\begin{array}{l}\text { Instructional Unit (defined by the Professor) } \\
\text { General Goal }\end{array}$ & $\begin{array}{l}\text { Natural Numbers } \\
\text { Perform Operations with Natural Numbers }\end{array}$ \\
\hline Unit/Subject & Goals & Time \\
\hline $\begin{array}{l}\text { 1. Fundamentals } \\
\text { 1.1 Addition of natural numbers. }\end{array}$ & $\begin{array}{l}\text { Allow understanding of basic opera- } \\
\text { tions concerning the categorization }\end{array}$ & 45 minutes \\
1.2 Subtraction of natural numbers & of numbers in natural sets. \\
1.3 Multiplication of natural numbers & & \\
1.4 Division of natural numbers & Review concepts and generate & $1: 30$ (one hour and \\
Review and self-evaluative activity & & thirty minutes) \\
\hline
\end{tabular}

The discipline teacher made available to the student her material and reviewed the whole matter during the making of the materials and exercises. In this way, the guidelines of Section 2 for the production of Accessible Learning Objects were followed and made the choice of the Computerized educational tool for the teaching of Mathematics.

In the planning phase it was defined that the discipline teacher would first administer the content and in a second moment, the students would practice in the laboratory using the objects of learning. The professor of the discipline applied an evaluative test before and after the use of the objects to measure the knowledge and level of learning obtained by students. The main objective of the evaluation was to evaluate the impact, to do pedagogical interventions and measure the contribution of the ALO.

Preparation of the lessons plan was carried out by the teacher of the Mathematics discipline in conjunction with the student responsible for the ALO elaboration. At this moment, was defined the content (calculations with natural numbers: mathematical operations) to be implemented in objects. As well, the duration (one hour per week), local (Computer lab), methodology (Interactionism) and shift (afternoon). The practice was accomplished in 6 (six) lesson, where four lesson were related to content teaching and two revisions, according to the schedule presented in Table 3.

Fig. 3 illustrates an example of the Accessible Learning Object developed to attend the lesson of Unit 1 (according to Table 3), referring to the basic operations (addition) on the natural set, to add two numbers, developed in the Scratch program. Fig. 3 presents one of the simple and intuitive interfaces of the ALO that aims to emphasize mathematical operations. For more dynamism, there was the insertion of a guide character to interact with the students. In the operations screen, feedback is presented to the student, with information regarding their errors and correctness, and the value of their partial grade.

Fig. 3 (in Portuguese). Example of ALO1 - Basic Operations - Addition (Question: Enter Result: - Students enter with the result and send, then the field's error or correct are filled, according to the answer informed. And the value field is informed so that the result is confirmed).

Learning Objects presents a clear title, the textual description theme and the content in sources that afford the user visibility, the alternative media (Macedo and Ulbricht, 2012), Thus as, the complete transcription: textual and audio, that describes the scene 


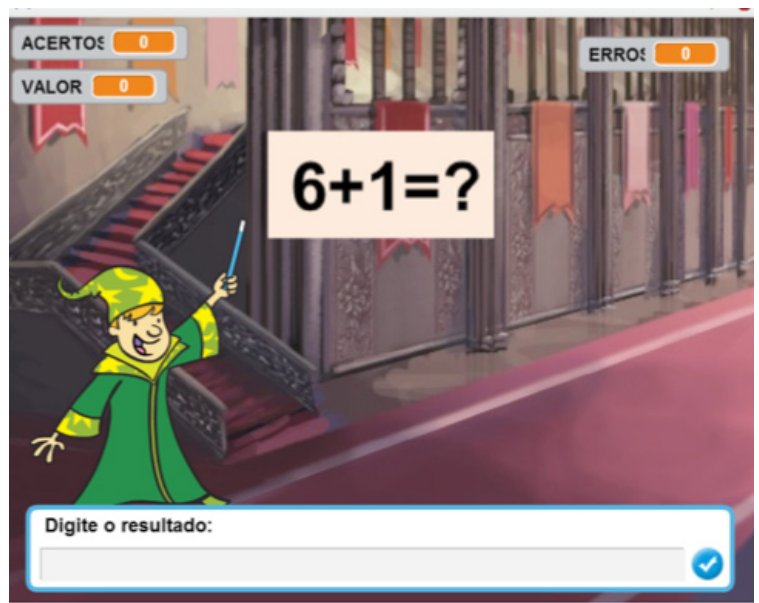

Fig. 3. Accessible Learning Object - Interface: Operation Addition.

and speeches that occur in the environment (sounds and movements), relevant factors to understanding of the content.

Mathematics teacher and the trainee in teaching had the responsibility to conduct students in the practice of their activities. They applied teaching methods so that the students to overcome the fear of Mathematics and learning, which often prevails in the children and adolescents' population. In this way, it was possible to accomplished improvements in the objects after its application, aiming to adapt the objects with the expectations and needs of the students. Constant orientations and observations were made in relation to use of the object.

Fig. 4, it is possible to visualize the students in the Computer Laboratory, accomplished the activities and using the ALO.

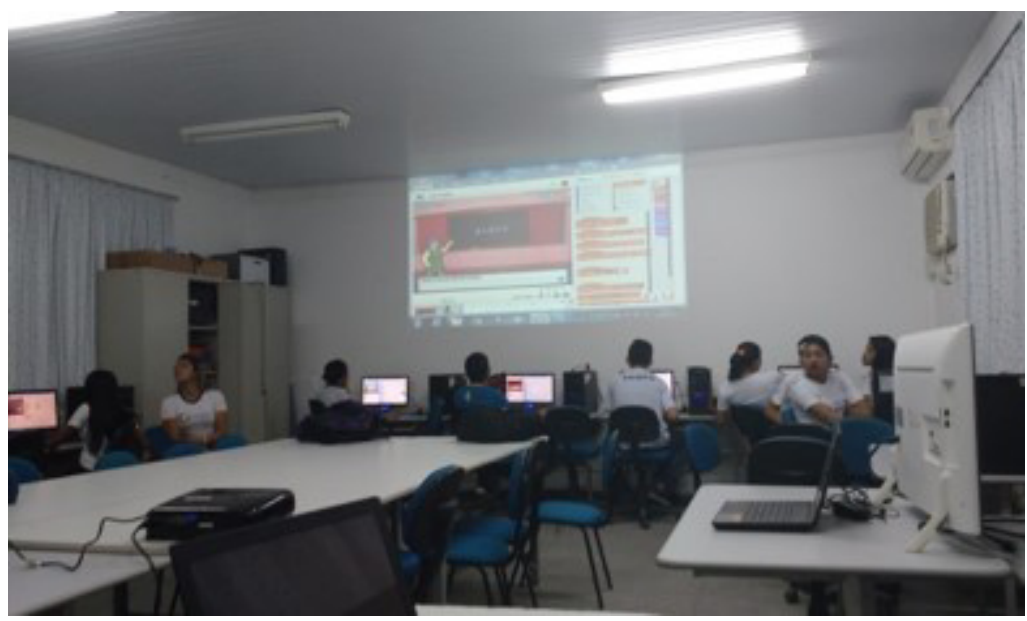

Fig. 4. Students in the Laboratory: Inclusive Model Application. 


\section{Results and Discussion}

As result obtained, we can observe that in all the lesson, the students studied the subjects, presented in table 3, from the accessible learning objects and they could have the Professor's support to solve any questions. In this sense, was possible to observe the great acceptance of the objects not only by the students but also by the discipline teacher, who participated effectively in the activity and felt motivated to develop more learning objects to attend the other instructional contents that would be taught.

Accessible Learning Objects developed in $92 \%$ of the cases, corresponded to expectations and attended the requirements and objectives defined in the planning. Therefore, it is important to emphasize the importance of developing digital educational resources.

ALO validations were accomplished through of the Evaluation: Learning, Teaching, Usability, and Accessibility with help the specialists.

We used the same criteria described by (Mourão and Netto, 2018b), generating four types of questionnaires. The evaluations lasted approximately 25 to 30 minutes, where the evaluators interacted with the students and made observations to obtain the data.

Learning Evaluation suggests that the student has already seen the content before applying ALO and that the teacher may be active during the process (Mourão and Netto, 2018a). In this sense, this evaluation has as a goal, to measure the performance and knowledge obtained by students, in relation to content applied. Fig. 5 shows the results obtained in the learning evaluation.

Learning Evaluation analysis, verified that there was $98 \%$ of learning development and that the objects show feedback of the activities accomplished, characterizing a teaching strategy, defined in the planning. Therefore, the results also showed that there were



Fig. 5. Learning Evaluation Result. 
adequate encouragement and support to the students and effective feedback provided by the teachers. Thus, 99\% affirmed that the exercises are adequate, $100 \%$ that the object presents challenges. About $97 \%$ of the object is appropriate to the target audience, $96 \%$ that the objects have a clear presentation, and also $98 \%$ reported that the language used favored students' understanding.

Teaching Evaluation refers to the adequacy of the objectives and contents, reuse and quality of the material developed, and defined in the planning stage. Fig. 6 below shows the results obtained in this evaluation.

Teaching Evaluation analysis, the results showed that $98 \%$ of the objects were adapted to the defined learning objectives, $89 \%$ also presented adequacy of the contents ministered in the room considering the profile of the students. However, it is important to note that $78 \%$ of the objects were actually able of possibility of being reused in other pedagogical contexts. In this sense, Benitti (2018) affirmed that reuse is the reason why much of Learning Object Technologies exists. The ALO also can be used for a diversity of students, adapting content or adding items. Regarding the quality of objects, $90 \%$ expressed that there is quality regarding the presentation of ideas, the accuracy, and precision of the content, to the level of detail and significant ideas.

Usability Evaluation corresponds to the quality of software or educational resource with regard to veracity, precision and balanced presentation of ideas. The items used in evaluation are based on the Nielsen Heuristics and were cited by Preece et al. (2002).

Fig. 7 shows the results obtained in this evaluation.

Accessibility Evaluation, thereabout $60 \%$ of interviewed affirmed that the interface of the object is simple and intuitive and that there is tolerance of errors. Also $64 \%$ related that information is perceptible, $80 \%$ reported that there is a low physical effort, that there is room for use and interaction, and that there is the efficiency of use, productivity, and flexibility. Another 75\% affirmed that learning was easy, 100\% reported that objects were useful, $82 \%$ reported communicability, and $50 \%$ reported safety in use. The object was well evaluated in this criterion, of use with medium-high quality, in relation to the presentation of its writing and editing, with respect to individuality and ease of use and



Fig. 6. Teaching Evaluation Result. 
learning. In this criterion the ALO presented clear instructions, was motivating and engaging, its appearance was defined as attractive, with flexible and interactive style.

As shown in Fig. 8, Accessibility Evaluation allows evaluating best practices for educators involved in the creation of learning resources.

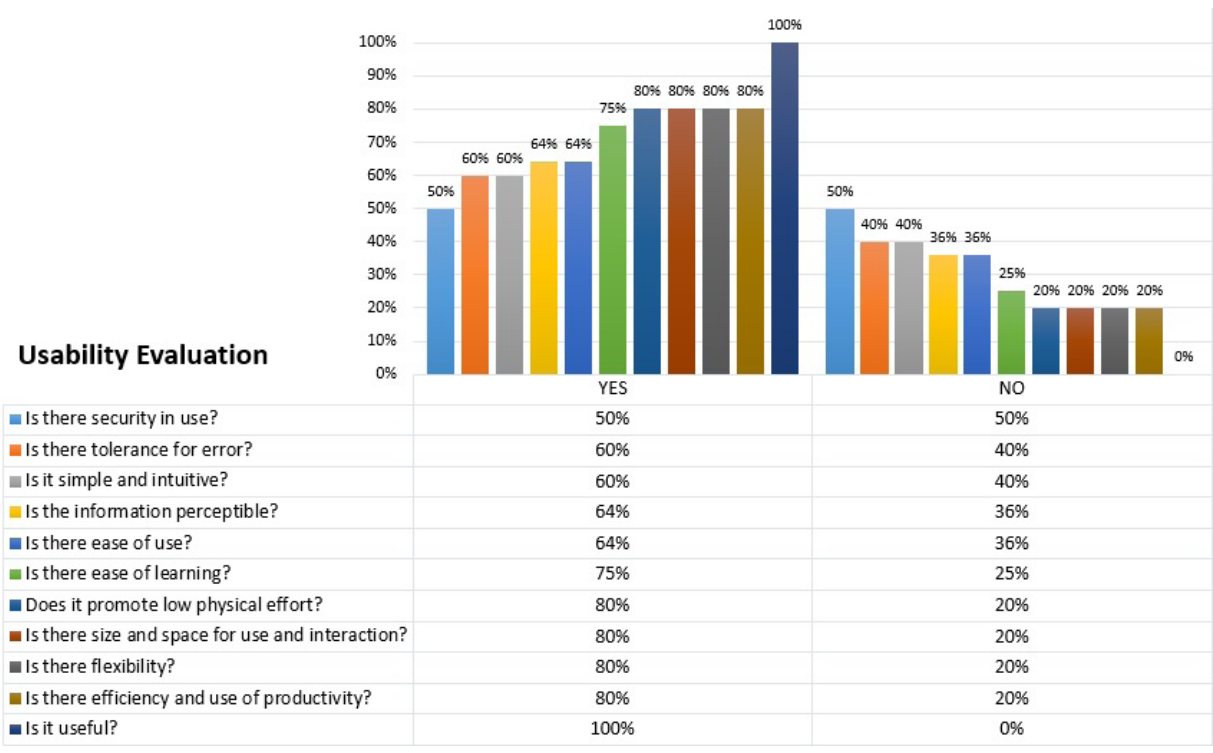

Fig. 7. Usability Evaluation Result.

\section{Accessibility Evaluation}

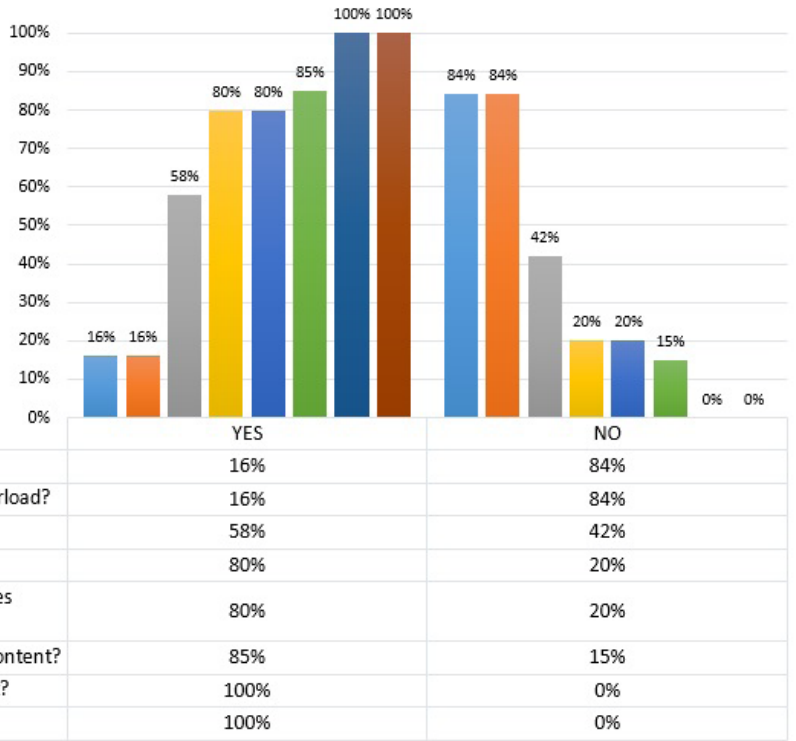

Fig. 8. Accessibility Evaluation Result.

\begin{tabular}{|c|c|}
\hline Does objects have content in pounds? & $16 \%$ \\
\hline Is there a visual pollution or information overload? & $16 \%$ \\
\hline Is it compatible with assistive technologies? & $58 \%$ \\
\hline Are images of quality? & $80 \%$ \\
\hline $\begin{array}{l}\text { Does objects use proper color and font shapes } \\
\text { (without serif)? }\end{array}$ & $80 \%$ \\
\hline Does objects have description for non-text content? & $85 \%$ \\
\hline Does images help understanding the content? & $100 \%$ \\
\hline Does images have explanatory text? & $100 \%$ \\
\hline
\end{tabular}


Accessibility Learning analysis $100 \%$ of the evaluators report that the images help in understanding the content and that they have explanatory text. However, $85 \%$ said that ALO have a description for non-text content, $80 \%$ that objects use colors and fonts appropriately, and report that images are good qualities. Although, it is important to note that only $58 \%$ said they were compatible with assistive technologies and only $16 \%$ presented visual pollution and information overload.

In addition to the evaluative questionnaires made by the specialists, the group accomplished summative evaluations through the pre and after test. In the first one, about Mathematics issues, especially in relation to the same instructional unit, where the class presented an average of 4.5 in the pre-test, and after the application and use of the Accessible Learning Object the class average increased to 8.4.

When comparing the initial with the final average, a positive evolution is observed, which represents improvements in learning and the maximum assimilation of the content. Thus, after the use of ALO, the students presented an above diagnosed performance, interacted more with each other, and helped the student with hearing impaired, providing a collaborative and cooperative educational environment. In this sense, the class presented positive points in relation to performance and interaction.

Descriptive analyzes of data show that the use of technological resources in the classroom generates positive impacts on student learning. Thus, its allow, which social and digital inclusion, be reflected in the educational aspects, mainly in the construction of knowledge.

\section{Conclusion}

This paper presented the student experience during her period of Supervised Internship. The application happened in a class of 8th year, of the afternoon shift, composed of 40 students in the age group of 12 to 14 years, where one student had a hearing impairment. The object was developed to work calculations with natural numbers of the Mathematics discipline. In this sense, the development of language in children with hearing loss occurred in a heterogeneous way.

The student in supervised internship concluding undergraduate Computer education developed an Accessible Learning Object following the Inclusive Model proposed by (Mourão and Netto, 2016). Thus, contributing to the teaching and learning process, developing their skills and competencies. The methodology used was precise and objective. The steps defined were important to: comply with the schedule; accomplish pedagogical interventions; and measure student performance.

Students who are deaf or hard-of-hearing present difficulty, because the loss or reduction of the sense of hearing impairs children's ability to hear speech, and consequently to learn the uncertainties of the spoken language of their environment. In this sense, the children hard-of-hearing present difficulty, interacted with their colleagues and solve the issues presented to them through the learning object. Consequently, they were encouraged to solve the exercises and develop their mathematical skills. In this sense, the proposed methodology supports the application of Inclusive Model in classroom by means of ALO developed. The viability of the methodology was obtained 
through of writing tests to measure student learning, before and after the application of learning objects. Besides, most students considered motivating to study through learning objects, as well as considered that the objects presented a practical view of the concepts studied.

The results obtained by this work contribute to support cooperation and collaboration in teaching and learning processes, through the dynamic, collaborative, and inclusive computational environment. This way, encourage other teachers and academics to build learning mechanisms or use educational tools that will collaborate with improvements in the teaching and learning process of the various curricular contents, promoting diversity and stimulating the adoption of inclusive education.

As future work, we intend to reapply the methodology with students' present other disabilities, and with other disciplines.

\section{Acknowledgements}

We would like to thank the State University of Amazonas (UEA) and Federal University of Amazonas (UFAM) located in Manaus, Amazonas, Brazil, for the support for realization of the doctoral research project, which this paper belongs.

\section{References}

Barbosa, E.F., Maneghetti, R.C. e Ponte, L. (2009). NUMRAC - Um Objeto de Aprendizagem como Apoio ao Ensino de Matemática. In: XXII Simpósio Brasileiro de Informática na Educação - SBIE. Florianópolis SC. (in Portuguese)

Benitti, Fabiane. (2018). A Methodology to Define Learning Objects Granularity: A Case Study in Software Testing. Informatics in Education. 17. 1-20. 10.15388/infedu.2018.01.

Bianchi, A.C.M., (2005). Orientação para o estágio em Licenciatura. São Paulo: Pioneira Thomsom Learnig. (in Portuguese)

Borges L.C.L.F., Araújo M.R.R., C. Maciel and E.P.S. Nunes, (2016). Participatory design for the development of inclusive educational technologies: A systematic review. IEEE Frontiers in Education Conference (FIE), Eire, PA, 2016, 1-9.

Brazil (2016). Ministério da Educação. Diretrizes Curriculares Nacionais para os Cursos de Graduação na Área da Computação. Parecer CES/CNE 136/2012, homologação publicada no DOU 16/11/2016, Resolução CES/CNE 02/2015, publicada no DOU 28/10/2016. (in Portuguese)

Forlin, C., \& Chambers, D. (2013). Inclusive education for students with disability part two: A review of the non-government sector in Australia, research report prepared by the Australian Research Alliance for Children and Youth for the Australian Government Department of Education, Employment and Workplace Relations.

Freire, P. (1996). Pedagogy of the oppressed, NY: Penguin.

Kuřina, F. (2008). Může být školská matematika matematikou dobrou? Pokroky Matematiky, Fyziky a Astronomie, 53 (4), 322-335.

Macedo, Claudia M.S, Ulbricht, Vânia R. (2012). Accessibility Guidelines for the Development of Learning Objects, Procedia Computer Science, Volume 14, 2012, 155-162.

Modeste, S. (2016). Impact of Informatics on Mathematics and its teaching. In: Gadducci F., Tavosanis M. (Eds), History and Philosophy of Computing. HaPoS 2015. Springer, Cham, 243-255.

Mourão, Andreza B., Netto, José Francisco. (2016). Modelo Inclusivo de Desenvolvimento e Avaliação de Objetos de Aprendizagem Acessíveis para o Ensino Superior em Computação. (CBIE/SBIE 2016).

Mourão, Andreza B., Netto, José Francisco. (2018a). Inclusive Model for the Development and Evaluation of Accessible Learning Objects for graduation in Computing: A Case Study. In: FIE 2018 - 48th An- 
nual Frontiers In Education Conference, 2018, San Jose, California. Proceedings of the 48th Annual Frontiers In Education Conference. IEEE.

Mourão, Andreza B., Netto, José Francisco. (2018b). MIDOAA: Inclusive Model of Development of Accessible Learning Objects. In: FIE 2018 - 48th Annual Frontiers In Education Conference, 2018, San Jose, California. Proceedings of the 48th Annual Frontiers In Education Conference. IEEE.

Nagyivá, Ingrid. (2018). Analyzing the Different Approaches in Mathematics and Informatics for Solving a Task and Educational Implications. Informatics in Education. 17. 61-75. 10.15388/infedu.2018.04.

Preece, J.; Rogers, Y.; Sharp, E. (2002) Interaction Design: Beyond Human-Computer Interaction. New York, NY: John Wiley \& Sons.

Resnick, M. et al. (2009). Scratch Programming for All. Communications of the ACM, v. 52, n. 11, p. 60-67.

Shimohara, C. e Sobreira, E.S.R. (2015). "Criando Jogos Digitais para a Aprendizagem de Matemática no Ensino Fundamental I.", Anais do Workshop de Informática na Escola. (In Portuguese)

Tambychik, T \& Subahan, T. (2010). Students' Difficulties in Mathematics Problem- Solving: What do they Say? Procedia Social and Behavioral Sciences. International Conference on Mathematics Education Research (ICMER).

Wiley, D. (2001). Connecting learning objects to instructional design theory: a definition, a metaphor, and a taxonomy. In: D.A. WILEY, The Instructional Use of Learning Objects.

Wolfram, C. (2010). Teaching Kids Real Math with Computers. New York: TED Conferences, LLC.

A.B. Mourão is Professor in the Department of Informatics at the State University of Amazonas (UEA) and PHD Student in the Group the Informatics in Education at the Federal University of Amazonas (UFAM). Her primary research area relates to Inclusive Model and Accessible Learning Objects.

J.F.M. Netto is Professor in the Institute of Computer (ICOMP) at the Federal University of Amazonas (UFAM). Him area relates to Artificial Intelligence, Mathematics, and Learning Objects. 